\title{
GLOBAL GOVERNANCE CAUSED BY NEW WORLD ORDER
}

\author{
Zerrin TOPRAK KARAMAN* \\ Asuman ALTAY**
}

\section{Introduction}

All through history, states tried to keep their national interests and took whatever measures it deemed necessary to ensure its presenvation. They formed blocks to be more powerful and to control each other, but this in turn, only enlarged their field of war. Today, wars, defence costs and defence technologies are serious expenses for the national economies and are disadvantageous for humanity.

Development and improvement have great importance in a bipolar world. Within the frame work of "development/underdevelopment" dilemma, the division of the world into two groups brings very serious problems. Especially unequal and unjust world order becomes dangerous for providing common peace and security. This is a period which interests everyone in the world. Thus, doing nothing is very luxurious. A search for achieving peace, security and humanitarian values is unavoidable.

Humanity has the energy to cooperate for common interest, but what kind of structure can minimize the international disputes? In fact, the base of problems is hidden in organization for peace. Producing a participating and democratic system starting from national-local organizations to supranational organizations seems to be the key for success. This study which takes agreement as the basis is developed in three sections. The present conditions were assessed and then the question of "what will be?" and "what should be" were taken into consideration. Firstly, the significant developments of the world were summarized and the character of coalition activities and the reasons of failure despite organizations were determined.

Secondly, it was examined whether a multinational world order which necessitates a different globalization was obtained due to rise of nation states in the

- Prof. Dr., Dokuz Eylül University, Faculty of Economics and Administrative Sciences, Department of Public Administration.

* Assis. Prof., Dokuz Eylül University, Faculty of Economics and Administrative Sciences, Department of Public Finance. 
seventeenth century and their strengthening in the eighteenth century and the development of the relations between them.

And thirdly, the importance and the functions of international organizations were examined and their effectiveness in global order was questioned. In this section, it was determined that the environmental ideology has become a center and besides the environmental right and human rights make sense only when taken jointly. Also interorganizational agreement was examined and the study was completed by a model towards a global order supported by international organizations. Global Order Model covers a period from the national states to the global international organizations.

\section{The New World Order and Global Governance}

As we are on the edge of the twenty first century, the societies have become more willing to establish an international balance of powers. Will they be able to achieve this balance? How can a balance of powers achieved and by which means? This issue will be examined in the following history of globalization.

\section{History of Globalization}

All through history, countries have passed through various globalization periods in different scopes and sizes: In the Far East, particularly globalization of China and India, in the Mediterranean area, comprehensive and unique globalization of countries such as of Egypt, Hellen and Roman Empires and even globalization of Christianity can be mentioned. However, "globalism" as we mean today, in other words" globalization of the West" appeared as the West geographically separated itself from the East. Globalization of the West being different from the East, have coincided with the Renaissance and later with the Enlightment periods.

Globalization, gaining a meaning with the concept of "Westernization", is an unavoidable phenomenon and a period in today's world. Assessment of the development stages within the Western approach did not arise today. In the mid of the eighteenth century an economical development started in England and became succesful in a very short time. The economic development in England have determined destiny of all the economical incidents of the future. In fact the economic development in England have caused some countries to enter a development stage and some to enter into an underdevelopment stage, because their technical and corporate structures have not adapted to the new economical system. Going through economic development the Western society became "an industrial society" from "an agricultural society".

1 Jean Maillet, 18 yy'dan Bugüne, Iktisadi Olayların Evrimi, translated by Ertuğnul Tokdemir, Remzi Kitabevi, Isianbul, 1983, p. 33-39. 
Regarding the above mentioned dynamics with the industrial revolution in the West, countries are grouped as developed, developing or underdeveloped. The industrialized countries exerted economic, political and cultural influence over the agricultural ones and passed through a globalization period called as globalization of the West. The underdeveloped countries of the East, the North and even some of the South contributed to globalization of the West in terms of usable sources (particularly with the use of natural sources and the displacement of old technologies to these countries).

Globalization period of the West is a geographical development, and so it is called "the period of horizontal globalization". However, the rise of the nation- states in the seventeenth century, which have strengthened in the eighteenth century and the development of relations between the nation-states, have necessitated a different period of globalization. Thus, looking at globalization of the West from the nationstates approach, it could be told that globalization is a result of the organization of industrial societies, because there is a connection between the periods of nationalism, imperialism and of deployment and freeing from imperialism².

Globalization period of the West caused a wide range of multi-cultural "Westernization" activities within time. Thus today, Westernization has become the basic aim of globalization. The West has achieved economic and political developments which provided a change from a "feudal" system into a capitalist system. For achieving capitalism, first of all the West established national markets and the nation-states. It also established a harmony between the national markets and states under a political regime of "democracy" and so today's West has emerged".

The development of industrial societies into "informatory societies" and the development of information technologies have started the period of horizontal globalization in the edge of the twenty-first century. The world involving inharmonious nations in different sizes, development stages and political-economical systems is going towards multinationalization, while nations are getting closer with political, production and trade relations.

Within economic, socio-cultural and political aspects, several values of civilization "horizontally" spread in the world from the most primitive to the most modern societies. Like the consumption of coca-cola, blue-jean and hamburger, the consumption habits are unlimitedly widespread by means of communication especially in sectors of food, textile, etc. So, a step towards a global system is already taken. A

2 Ernest Gellner; Uluslar ve Ulusçuluk, translated by B.F. Behar, G.G. Ozdoðan, Insan Yayınları, Istanbul, 1992, p. 84.

3 Ali Kılıçbay, "Globalleşmenin Program: Batılıaşma" Ekonomik Yaklaşım, Vol. 4, Issue 9, 1993, p. 17. 
second step in this period is "vertical globalization", which has to be adapted to the global system of nation-states. Including the out of state units to the international system has made up vertical globalization period. Vertical globalization has emerged as a result of unlimited socio-economic establishments and the change of nation-state. Thus, globalization becomes meaningful as the will to take place in the global system increases. So the state is not affected by the developments and the changes in the world economy and by every change in products.

In the seventeenth and the eighteenth centuries, due to communication difficulties and technological deficiencies, for a long time international relations could not be globally executed. However, in the last quarter of the twentieth century globalization has obtained a different mission. But in order to understand globalization period of today, it is necessany to examine the balance of economic-political powers of earlier periods.

\section{Towards a MultiNational World}

Today, "Globalization" the key word in explaining and describing some of the international periods, finds its meaning in "the New World Order" concept that is "expected to create a conventional atmosphere" in the world. "The New World Order" can still be considered as a hypothesis that is not proved under present conditions.

Today, a new construction in the world order is taking place. Globalization process is considered as a new world order to be reconstructed which carries both economic and political meaning regarding its functions. In order to reach at the determined targets of globalization an environment that is approved by the international (external) as well as national (internal) actors is necessary.

Globalization process is generally considered as the "model" where the disputes, tensions, conflict and crisis which are always present in international relations are avoided. However, we cannot consider "globalization" as a system which completely avoids all the problems, and which pulls them back to "zero" level. This is against human nature, it is an utopic approach. However, within globalization process in order to invite or provide "agreement" on good will, the use of effective factors can be discussed. Thus, determining and practicing supranational targets and principles is very important. At this point, a sanction to avoid being capricious is required.

During this period of reconstruction or globalization large integration movements are also observed in the world order. The speed of the integration movements does not remove the target of establishing a global world as one economic unit. In other words, the world emerging as one economic unit is not contrary to the new global order approach. 
Regarding the civilization values the principles should be decreased towards the top of the pyramid as the universal values become more important (universal norms: total of principles, values, believes). The reason is that the various cultural and social values of nations are not transfered to supranationals. However, common values of nations like human rights (environment, settlement, working, etc..) should be standardized which are possesed by all nations. Taking all the values to the top will lessen the participation of nations and increase their objections of being different. This in turn will reduce the success of targets expected in globalization. In the meantime, there may be various values at the bottom which can be acceptable by every nation at regional level.

The power of center in the nation- state and of the bureaucracy are questioned. In the twenty-first century under democracy, the political-administrative decision areas, playing mostly interfering roles over the market decision mechanism, will be restricted and the functions of nation-state will be reviewed. Some of the authorizations will be left to present or developing international organizations and some to local governments. Both developments require the spread of democracy, concrete organizations and rules supported by democracy.

It is not easy to match the logic of globalization with present representational democracy. Today, in countries governed by democracy, problems of representation exist both at local and central levels. This phenomena is an important obstacle for globalization. In fact, unablity to solve the representation problems in democratic ways causes weakening of nation-states. This makes the hypothesis that the twentyfirst century will be the post-nation-state century.

It is discussed above whether a multinational world system has created a new world system or not and whether in such a system the nation-state will leave its place to a new supranational construction. Under this discussion we may further ask the following questions:

- Does capitalism get stronger through "decentralization" process?

- Does imperialism look for a new structure through globalization?

- Will there be a world of international peace and cooperation through globalization?

Among the above mentioned questions, the questions of imperialism may actually sound ideological. But imperialism an expansionist ideology which has importance in international history and which is carried to modern age (20th century) by developed industrial nations instead of old empires. Will globalization take the place of imperialism in the twenty first century? This question should be regarded in two ways. First of all, imperialism had been a period where the economic factors were mostly used for political means. On the other hand, globalization is the modification of imperialism which was used as economic means. 
An important point in this modification of imperialism, is whether ideologically globalization process takes the place of imperialism. A positive answer is possible. However, dividing the world into two as the East and the West is against the concept of "Westernization" of the twenty-first century. Also, we can not say that the economic and political power centers in the world are growing proper to the old system.

The "development-improvement paradigm" ruling over the world after the collapse of the Eastern Block in 1989, is a liberal economic and political system based on market economy. So, in the twentyf-first century, globalization process will be seen with the development of liberalism in politics and market economy in economics. Also the reconstruction of central and bureaucratic structures of the nation-state and the adaptation to above mentioned global order will be unavoidable for the states existing in this period.

However, the efforts of countries to adapt to global order, may be avoided by their unwillingness to change their traditional, conservative and ethnic identities and to disintegrate into global system. While there is resistance to supranational structures, different identities and cultures brought by global order, and hard adaption to abstract concepts like "world citizen", "world culture", and further more finding them unrealistic, can we avoid international conflict, and disputes? At this point a new analysis is required to examine:

- the power relations between societies, and

- the distribution of capacities on earth and the avoidance of inequalities

A second point which needs to be mentioned here is that with globalization period at international level the structural characteristics of intersocial relations becomes important. In other words, the necessity of keeping local autonomies becomes undiscussable.

The above mentioned points show us that globalization period is a new version of capitalism. This causes "new liberalism" (in economic and political sense) to become important. However, it's true that new liberalism still having deficiencies at the end of the twentieth century, does not cancel the need for a state (inspite of all its inconveniences) both materially and morally. Also, new liberalism did not bring anything new to the classical democracy. How will the present understanding of democracy be adapted to "new liberalism" and "global order"?

\section{Is it the end of the Nation-State? (Is nation state in crisis?)}

The rule of capitalist economy in the world causes capitalism to exceed the national limits and to spread worldwide. This is a globalization process and it establishes supranational rather than international relations. Multinational relations tak- 
ing the place of mutual interstate relations, damage the classical character of nationstate. In other words, nation-states have started to leave their usual ideological and political roles since the beginning of the 1990 s and take their place within a new economic cooperation.

If the state is determined to be "a society based on common culture having its own customs and legal system, way of production and art it may adapt to changes brought by "the global order" due to the "culture factor". If the race factor comes forth as well as culture, then problems regarding globalization may be observed. In other words, approaches to explain the nation-state or racist-nationalist elements used in practice will be in dispute within the planned global order. Here, also using the right of sovereignty of nation-state becomes significant. When the use of sovereignty is examined it is seen that the nation- state will not have an unlimited right of sovereignty.

In the seventeenth and the eighteenth centuries, it was considered that the power which was hold by the state and separated it from the other organized communities, was the authorization of the state sovereignty depending on no control and taking the form of certain command power. Jean Bodin, in his book called "De la Republique, 1577", for the first time, explained the sovereignty concept as a regular power completely owned by the government. Moreover, the sovereignty formulized by Bodin was not unlimited, it spontaneously restricted itself by codes. However, an unlimited power description was made by other authors ${ }^{5}$. In fact, no other authority taking place over the state means that there are no rules which must be obeyed by the states. However, the social and historical requirements made the international law order compulsory which was first started to be settled in Europe by the Westphalia agreements ${ }^{6}$.

Each state has its own right of sovereignty within its borders. Consequently, international relations become extremely necessary. Otherwise chaos is produced and this may cause states to lose a lot and even their sovereignties?

In fact, the truth laying under this change is the change occuring within the fluidity of capital. These changes also altered the functions of nation state or at least forced them to, because one of the most important developments in the near past is "internationalization of production" or in other words" globalization of capitalism". The

Süleyman Akdemir, Devletin Unsurları ve Kuvveller Dengesi, Istanbul, 1991, p. 173.

See Oppenheim, L. (Lauterpach. H); International Law, A. Treatise, 1961, supra note 1, p. 20, transfered by Aslan Günduz "Eroding Concept of National Sovereignty: The Turkish example" Marmara Joumal of European Studies, Vol. 1, 1991, p. 100.

Huseyin Pazarcı, Uluslararası Hukuk Dersleri, 2nd Book, 3rd Edition, Ankara, 1993, p. 18-19.

Aslan Gündüz, p. 100-101. 
increasing movement of capital caused various levels like production, research, development, design, marketing and management to be distributed to different places. And this is such a power that may cause the old closed nation-states to turn into "nation states that are open to global integration".

As a result of the collapse of the Keynesian economy, starting in the 1970s, functions of nation -states like redistribution and replanning became weak. The Keynesian solutions which ruled in the post-war period could not avoid the economic problems of the 1970s; an economic problem like "stagflation" especially shocked powerful economies. The industrialized countries can be characterized by the fast economic development and the low inflation in the post-war period ${ }^{8}$. In the 1970 s, the U.S. was simply the banker of the countries except for the communist block. However, the sudden increase in the petroleum prices in the 1970s caused the international financial system to collapse and affected the U.S. economy. Big deficits in trade balances of 1974-1975 were different from recession seen in the previous years. Because of the following reasons;

- Time for reaching global balance was likely to expand

- Economic recessions in that period increased the pressure of inflation

- Similar problems at equal times appeared in industrialized countries

- High price increases in energy, food and other basic goods were obtained.

The economic destabilization of the 1970s in industrialized countries started to get better since the 1980s. These years commercially started a positive conjucture in the world economy and trade. Neo-liberalism again became strong and the power, the authorization and the limits of national states again started to be discussed in these years. The will to make the world an economic unit and market, caused the expansion of actors and multinational corporations (MNCs), owing to very big financial and technological facilities. The MNCs form the "group dynamic" of modern capitalism and became the endogenous factor of globalization.

Globalization period involves important international developments, particularly as follows:

- Liberalization of trade of goods and financial markets

- Spread of direct foreign investments via international corporations

- Developments in regional agreements

8 Between the 1950 s and 1970 s, in industrialized countries, the annual actual growing rate was $4.7 \%$ and inflation increase $3.7 \%$ in average. 
Capital became international, in other words multinational corporations became strong parallel to general economic conjucture from the $1970 \mathrm{~s}^{\vartheta}$ and the world's economic abilities created the global order of the 1990s. This uncompleted order caused the industrializing countries to present their capital, manpower and market facilities to the above mentioned MNCs. And that made the production to be nongeographical and the international capital in those countries produce or increase the effects and control on manpower and decision mechanisms.

The nation-states, in order to adapt to the global order, entered an alteration period without hindering the capital. In such a structure the national borders are not important and the rights arising from the national sovereignty are removed. Of course, the nation-states will continue to exist in accordance with the new world order, because inspite of the only one world market or one world economic union forseen by globalization theoretically, it's not the same in practice.

In short, the-nation state did not become weak. It only entered into a period to adapt to the new world conditions. Thus, a nation-state model has been formed which is loaded by ruling, not hindering functions. It should be added that with globalization nation-state opening to the out of state units has not weakened. Removal of order, depending on the bipolar balance of powers (the U.S.- the U.S.S.R.), have strengthened the nationalist trends both in the Balkans and in the Caucasian based on ethnicity. While on the one hand, the new national states in these regions were established, on the other hand, the relations between nation-states gained clarity with the "power" factor as in history.

In the international system, the activeness of powerful countries forming the basic units of this system attracts the attention. All through history, countries in different geographic areas, having different population and development rates, economic and political regimes had various discord problems. This has produced hot war or cold war, but also sometimes cooperation.

After the Second World War, examining dominant powers of the twentieth century, it is observed the United States is powerful in the industry of weapons and in economy and politics; the Soviet Union is powerful in military and politics, and the West European countries are powerful industrially. Today, the economic powers of the world have a tendency to concentrate in different production areas.

The world order right before the twenty -first century is anxious to become a global order depending on blocks and regions. The inclination in the world for regionalization with blocks is an important step in developing free trade between the 
countries. These developments can be considered as a threat for globalization. The two new movements of protection and regionalization are the two important obstacles in front of globalization. If so, will the world trade in globalization period become less liberal and turn to trade blocks just contrary to what it should be?

It's true that the inclination like integration of national states in bigger associations while entering the twenty-first century has put its stamp on regionalization. Because, besides giving us an economic integration message as regards exceeding historically determined national states, the international integration movements also show which mechanisms to run to integrate ideologies and cultures. The European Union (EU) is the best sample on this issue. Besides the EU, other regional economic integration can be discussed, like NAFTA between the United States, Mexico and Canada; APEC (the Asia Pacilic Economic Cooperation) between Korea (SouthNorth), Japan, China, Hong Kong, Taiwan and Singapore in the Pacific area and ASEAN (the Association of Southeast Asian Nations) between Indonesia, Malaysia, Phillipines, Thailand, Brunei and Singapore ${ }^{10}$.

Looking from the above mentioned dimension, today the old north-south contradiction is no more geographical but rather gained an economic dimension. Economic blocks appear within North America, Asia-Pacific and Europe. Center of each block is the United States, Germany and Japan respectively. The potential leaders of the twenty-first century are considered to be the United States, Japan, China, Germany, Russia and India (as per their demographic characters).

These regional integrations in the multinational world could not provide the validity of a law proper to international community for establishing global balance. Primary reason for this is the effort of global balancing powers to externalize the regions which will negatively affect this balance or which will load large costs. This political preference arises from the unwillingness of powers, guiding mostly waste world economy, about assisting the underdeveloped and politically unstabilized regions. The powers of the new order are inclined to renew themselves at the center which leads them to form regional organizations and blocks. Today, the Western countries, beyond national structure, prefer regional organizations having "supranational" authorities instead of "national state". The major reason is to produce regions to attach to this system and provide supranational global order.

It's mostly true that the international organizations, founded for producing solutions to different international problems, etc. where the member countries don't have their own will-power, are directed by "central resolution powers". The requirements of

10 See Robert J. Art - Robert Jervis, International Politics 3rd Edition, New York, 1992, p. 388; Staffan Buvenstam Linden, Stanford, Stanford University Press. 
global order are not consistent with the non-democratic structure of supranational foundations as per their present status. Therefore, it is necessary to prepare the foundations, having supranational status as well as national state, to the global order.

In the twenty-first century, the power depending on national interest to become clear and the international organizations, particularly the United Nations and NATO, to become uneffective in practicing their aims, depend on their present status. In other words the effectiveness of powerful nation-states in the organizations in proportion to their power, requires the review of structure of international organizations' and the need to produce necessary solutions for changing needs.

During globalization process, with the enterance of classic state into reconstruction period with global or regional organizations having "supranational" authorities, the "nationalism" is expected to leave its place to "regionalism" depending on ethnic, cultural or interest union. On the contrary, today in some parts of the world there are reasons to weaken this hypothesis. Particularly after the collapse of the Soviet Union, both in Caucasia, in Balkans and in the East European countries ethnic movements have increased and the continuity of world peace and security and democracy fell in danger. Is the international society with its present status going back to the beginning of the twentieth century?

We wonder if the changes taking place at the end of the twentieth century reminding the First World War conditions can be the messenger of a new world war?

The twenty-first century world, under the different conditions from previous world, would not let a new world war depending on the national and ethnic identity conflicts, because the greatness of information and communication technologies which will rule over the world in the twenty-first century and the efforts of international organizations providing international cooperation, particularly like the UN and the NATO would not permit such a war to happen. Becoming politically democratic by the help of some organizations like CSCE (the Conference on Security and Cooperation in Europe) will avoid such a danger.

In our opinion, the reasons preparing this result can be examined in two major sections. The first arises from the structure of organizations and the second from the structure of the world outside the organizations. This structure is mostly formed by ideology. Here, there is need to review the characteristics of organizations. The reason to discuss the organizations here is that the international organizations are held responsible for establishing the new world order.

\section{International Organizations and Their Specifications}

After the World War Two, almost all the countries have participated in international exchange. As a result of this, integration to world economy became the ba- 
sic aim of each country. Thus, the base of a world that people have been longing for, where people, goods, ideas and even dreams will integrate or globalize has been founded. These changes leading all the nations into mandatory cooperation caused to consider societal life in supranational dimensions.

Nationalism which once increased personal freedom and happiness, today makes it difficult to adapt to these new conditions. Nationalism which once was the biggest pushing power in societal life, today seems as an hindrance. Political nationalism today has started to be against the necessities of human life. Now, the personal freedom should be handled, protected and organized at "supranational" level.

Organization of nations to solve the common international problems has led to the establishment of international organizations. Today, though international organizations are weaker than national states in many ways, compared to the facilities and authorities offered to them, they achieve important works and strengthen their presence.

The international political organizations has started in the second half of the nineteenth century. Beginning in this period particularly at the beginning of the twentieth century, two major developments took place which affected international life. The first one is the international cooperation, particularly economic cooperation, becoming compulsory for the existance of states and the second one is the change in character of wars and efforts towards peace. To give an idea, international organizations are examined below.

It is possible to classify international organizations according to different criteria:

(i) As universal or regional

(ii) As interested on a specific topic or on wide scope

(iii) As coordinator or supranational

Regarding the present international organizations, this classification can be shown as follows;

(i) Universal International Organizations, are not subject to any geographical restriction and are open to the membership of all states, e.g. the United Nations (UN), the Universal Postal Union (UPU).

Regional International Organizations are only open to the membership of regional states, e.g. the European Council (1945), the Organization of African Unity (OAU).

(ii) General and Political International Organizations, are not subject to any restriction with regard to their scope or have wide scope such as establishment of international peace, e.g. the United Nations (UN) and the European Council (1945). 
Specialized International Organizations are founded to act in a certain field. It is possible to subclassify these organizations according to their activity. (i) Economic and commercial (General Agreement on Tariffs and Trade - GATT); (Organization of Economic Cooperation and Development - OECC 1948 / OECD 1960); (ii) Military (North Atlantic Treaty Organization - NATO 1949 - the major military and politics organization in Europe); The Western European Union - WEU 1954); and dissolved Warsaw Pact); (iii) Cultural and scientific (United Nations Educational Scientific and Cultural Organization - UNESCO); (iv) Technical Services (International Telecommunication Union - ITU); (Universal Postal Union - EPU); (v) Health (World Health Organization - WHO); (vi) Labour (International Labour Organization ILO).

(iii) Supranational Organizations, The basic difference between the international organizations, only providing international coordination, e.g. OECD, and the supra-national organizations, e.g. the EU is that in supranational organizations some of the authorities of states are transfered to that organization.

Generally, international organizations showing a big "explosion" since World War Two within the complicated structure of the world, execute health, economic, social and environmental services, which cannot be achieved by the states inspite of the precautions taken in their own countries. In this sense, international organizations are likely to be a system produced by a multinational world structure. They also bring new methods for international relations and provide institutions and a base for dialogue to create harmony between state policies.

Besides, these organizations seem to be a step taken for the establishment of an international community which humanity had been dreaming for ages, instead of a multinational world order. In this way, they become means to provide a better world system to solve the common problems. In this connection, the international organizations, when assessed in term of their aims, show a double character. These organizations proved their success particularly in economical, technical and managerial issues and even within time it almost became impossible to think of a world where some do not exist.

Problems, above the regional and / or national scale, affecting the whole world has also globalized the responsibilities. Particularly the environment within these responsibilities have been developed by containing all the other economic and social activities and started to take place almost within the whole organizations mentioned above.

Environmental problem affecting the whole world is its determining character. The reason it became central is that it is above the ideological differences arising from the state systems and has the facilities to create "environmental ideology". This recognition has made organizationat cooperation stronger. This is summarized below. 


\section{Cooperation of International Organizations Under the Umbrella of "Environment"}

Environmental problems had made major changes in the international arena. For ages the security of the states had been examined in military terms. However, in the last ten years quite different type of a threat is emerging which is the "ecological security". The egological off-the-border violations are more actual from the military off-the-border violations and are expected to be realized at any time. The global side of environment is shortly examined below.

\section{The Role of Environment in Change Towards Globalization}

Today, while passing into the disarmament period, involving also economic factors, instead of the race of armament, the race of industrialism has taken a political meaning. Industrialism being supranational causes the environment problems to be arranged supranationally. That is why the principles of environment policy become effective in international policy and international policy in national environmental policy.

Within the economic and social policy, the approach to the management of natural sources directly and forcing environmental unity can be made in two ways. The first is made by means of investment programs without natural and environmental support, and the second by means of economical, social and institutional investments and encouragements. The attitude and activities of organizations/states related to environment also affect their other activities. The basic understanding is;

(i) to determine the comfort of today and future guided by the economic and social scales

(ii) to provide the proper use of human and natural sources

Being authorized and responsible, the national policy is very important, because the nation state meets both ecological and economic international problems and nation-state also frequently becomes desperate against the world economy and its problems.

The national state, though considered as the only large actor in global environment protection is in a weak status. This status arises from the world's economic structure. For instance, since a multinational organization organizing an automotive industry has a large network, it is difficult to control. Also, due to competition of not only the enterprises but also of the states in the world market, the tax exemption and encouragements considered as an advantage for industry may avoid the environmental protection. 
In short, it is clear that the central management alone is insufficient to provide all social needs and to avoid environmental problems. The firm bureaucratic structure of the central management causes delays in taking precautions towards the solution of problems and in their practice. Thus, the importance of actors responsible for the international environment protection becomes clear and the chance to avoid "community/social oppressions" where the state becomes desperate is obtained.

\section{International Organizations and Harmony in Environmental Policies}

Environmental deterioration is not a new fact. Today, the change in the environment which is clearly visible, appeared in the nineteenth century and continuously increased during the twentieth century. For a long time environmental deterioration is considered as a problem of the industrialized countries. Today, the developing countries are aware of their portion in environmental pollution. Consequently, this is a world problem and interests all the countries.

Classifying the human activities and their influence areas as social, economic and environmental seems no more possible, because there is economic, social, cultural and ecological interdependence between nations. From this perspective it is possible to explain exactly what the world union and cooperation means. It is not possible not to consider the efforts of international organizations to dissolve the environmental problems and to distinguish their functions. In other words, they perform collective work very well. Below, we will shortly examine their activities.

In the International Stockholm Conference held in June 1972 the issue of environment appeared for the first time and an atmosphere is prepared to create principles for sensitive management of our planet in terms of ecology. As a result of this first forum, in which the world leaders had discussed the issue of economic development in environmental harmony, the United Nations Environment Program (UNEP), acting as a catalyst in international cooperation for environment, was established. Also, in the declaration of Paris Summit in 1972, "to give priority to the protection of environment" was requested. Regarding the European Communities, a base of activities is settled.

On April 17, 1973, a commission of the European Union recommended to the Council "The European Communities Environment Activity Program". This program was accepted on November 22, 1973 as a declaration of the representatives of the member states. This program aims to reduce and to prevent environmental pollution, to improve the environmental quality and life and to bring joint action of the member states in international forums. It adapted the principle "polluter pays".

Between 1973 and 1976 the Council of Ministers of the European Union accepted many regulations regarding the detergents, the amount of lead in fuel, the ex- 
haust gases and the radiation. In 1972, the Commission issued the first report assessing the state of the environment. Thus, the Council decided to continue on the Community Environment Program. In 1975, the establishment of "the European Foundation for the Improvement of Living and Working Conditions" in Dublin is another step taken to improve the environment.

In 1977, the Commission issued its second report about the state of the environment. This report involved positive change in the policy of environment and the policies in rational use of natural sources. In 1978, the Union signed the Barcelona Agreement on the pollution of Mediterranean sea and the Bonn Agreement on the chemical polution of Rhen. In 1979, it participated in the agreement for the protection of the European Wild Life and Natural Habitat and in the following years, it accelerated the environmental protection policies.

The European Council has also been working on environmental issues for a long time. Regarding the problems like nature and air pollution that appeared with the development of the societies, the protection of nature and cultural inheritance and urban, and regional planning, the European Council leads on the application of the radical procedures. In 1979, the opening up of the agreement for European Wild Life and Natural Habitat, known as the Bern Agreement, to the signature of the member states, and the creation of environmental protection regions were the complementory and supportive elements to the work of the Council in this field. Thus, the stable regional economic and social development, the improvement of daily life, the rational use of natural resources, the protection of environment and the economical use of open spaces are among the main principles. The general environmental protection criteria of the Council is given below.

It is not possible to practice short term policies on environmental issues. So, the industrialized countries should guarantee the complementary projects and programs for development. The natural and/or local characteristics and the environmental effects of the projects are important. Thus, the studies for environmental development should be performed as soon as possible. For this reason, the Council, in their project and programs for environmental aid had taken decisions making it easy for the assessment of environmental values. (October the 23rd, 1986). These decision areas are as follows;

(i) to enlarge and encourage environmental protection,

(ii) to inform the public of the importance of ecological sources used for economic and social development,

(iii) to determine the importance of public awareness in environment protection and to provide public to assist in projects. 
In 1987, the report on "Our Common Future", known as the "Bruntland Report" issued by the United Nations World Environment and Development Commission supported the sustainable development efforts. On December 22, 1989, the General Assembly of the United Nations accepted the decree number 44/228, proposing a global meeting about environment and development. With the above mentioned general assembly decree, the member countries of the United Nations have agreed on the requirement of participation of all the countries and of procedures at every level on global environmental problems, such as the change of climate, the weakening of the ozone layer, the pollution of air, ocean and sea. The countries also emphasized the requirement of an effective international cooperation in research development studies related to sensitive environmental technologies. They agreed that all these global efforts also should support the economic growth and development in all the countries.

Moreover, another subject agreed on is that the countries that damage the global environment must be primarily responsible in removal of these damages.

In addition, in the program of the European Community in 1987-1992 period, the wholeness of environmental economic and social policies and the requirement to improve water and air quality in order to protect the natural sources are emphasized. In this program the importance of professional training and university education in environmental studies were also stated and the future responsibilities in protection of environment were highly emphasized.

On June 3-4, 1992, the United Nations conference on the Environment and Development which was held in Rio de Janerio, Brasil, is the first conference on environment and development, which brought the state presidents and prime ministers together at global level".

In this conference, in order to establish a new and neutral cooperation, between the key sectors in society and the people, the states adapted the 27 principles of "sine qua non" for the global world including the right for healthy life, the right for authorization and responsibility, the right for development, the right for development with environmental protection, the right to remove poverty, priority in accordance with development, cooperation, production-consumption-population, exchange of information, to learn and to participate regulations and standard economic cooperation, responsibility and compensation, cooperation in wastes, security principle, environmental costs, environmental impact assessment, cooperation, support, participation

11 Agenda 21, United Nations Conference on Environment and Development, ACONF. $151 / 4$ (Part I, II, III, IV), 1992, The Rio Declaration on Environment and Development, United Nations Conference on Environment and Development, ACONF. $151 / 5 \mathrm{Kev} .1$. 
of women, importance of youth, supporting local people, supporting societies, respect to international law, peace and environment, solution of disputes and good-will. In fact, as mentioned above cooperation among the international organizations in environmental protection has been established. Finally, on June 3-14, 1996, Habitat II Conference has been realised supporting for this ideology.

As long as economical cooperation for common good is obtained, it is possible to establish a political cooperation for the world interest. The problem can be solved with the support of a good organization and infrastructure.

\section{The Model of Global International Structure}

When the structure of the organizations in the world are examined, it is observed that they are grouped as single and multi-purposed service organizations. Whether single or multi-purposed both types intersect each other in terms of their functions. Here, the effectiveness of having similar functions by several organizations is discussable. In cases where standardization is obtained on these functions there is no need to be disturbed. A good coordination may increase the effectiveness. The world has become smaller in terms of communication, but the variety of works increased and became common for all. The second issue is the international and supranational character of these organizations.

The basic international organizations today, seem to be organically tied to each other and their duties are more or less similar. It seems if one of them is removed, the other may to take its place right away. In our opinion, when the other service organizations are taken into consideration, this condition is both extravagant and makes it difficult for coordination. Though it is expected that the competition will bring cooperation in market conditions, it usually causes dispute in politics.

In general, it is possible to see three different Europe. The first one is the economic Europe of the European Union based in Brussels, the second is the defence Europe created by NATO and the third is the Europe involving issues like human rights and freedom produced by the Council of Europe based in Strasbourg. In spite of all the objections this situation strengthens the opinion that Europe is the center of the world and almost all international organizations has been established for the European interest.

If we are talking about a global world, then the equality of all the countries is important. As mentioned above, the failure of the organizations arise from the lack of confidence of countries in each other. As a matter of fact, NATO, at the beginning of 1994, has strengthened the relations between the middle, the east European coun- 
tries, the countries who participated in the European Security and Cooperation Conference (ESCC) and NATO countries and has produced a "Partnership for Peace" program in order to improve stability and security all over Europe. Partnership for Peace does not only reduce the division and disputes of the old enemies, but also brings a new ideal towards future with a new agenda. However, though the Partnership for Peace Program has created some ideals like increasing the security of all countries, providing no privilege to any country or providing no right to veto the participation of any other country, and makes no differentation between big and small countries, it definitely separates the membership of this program and membership to NATO and thus, prefers to keep its classic status- quo.

International organizations are not democratic regarding their structures of central decision. Thus, a structural political-administrative democratization is necessary. It is considered essential to provide the member states as an honoured member to have equal rights in participation and thus, remove the image of "the club of rich".

The important problem in reconstruction is the possible difficulty of the member states to accept this change. The reason is the probability of unwillingness of the "main members" who were used to be in "advantage" of this system in accepting the change. In this case, there can be intention to establish a new organization. However, this will cause uncertainity/inconfidence and loss of time. In order, for the organizations to reach at the universal targets, such unwillingness should not exist. The experience, facility and means of these organizations should be used.

In our opinion, there are three basic organizations having international character or close to having it: NATO, the Council of Europe and the United Nations. In the global system of the twenty-first century a new classification can be made.

They should have characteristics such as follows: political

NATO/Global Peace Organization; supranational, military-social, general-

Council of Europe/Global Council for Decision; supranational, general-political

The United Nations/Universal, supranational, general-political

The European Union/Regional-supranational, economic, general-political

The European Union, since it is considered as a regional organization, has not given the role of supra-organization in our "Global Theory", but its model is used. 
The Global Peace Organization/NATO; may be considered as the "World's Security Insurance". NATO has the necessary know-how infrastructure for providing security. Its name which sounds regional should be changed. It should be reconstructed for global peace.

The Council of Global Decision/Council of Europe; its name should be changed as Council of World Decision. As in the European Union, the states should give their authority for legislation and decision to the Council regarding the global issues which affect the whole world, like environment.

The United Nations; besides bringing the United Nations to a universal and a supranational status in the new world system, also it is essential to reconstruct the system which seems non -democratic and unreliable. Its name may be kept as it is, but it should have global economic and social-cultural functions.

The status of organizations such as "court of justice" which are essential for other functions like jurisdiction or surveillance may be reconstructed in accordance with this new situation. The improvement of the programs of other "international service organizations" like the World Bank and the International Monetary Fund (IMF) should be made based on the global interests on the new world system. In fact, there are some clues that the World Bank delays the reconstruction.

The control of the application of these rules may be given to "the international assisting organizations" which are mentioned above. The states must control the practice of supranational decisions by means of their national authorities and in case they fail they must apply to international service organizations and use their facilities. Besides, they are responsible for informing the global supranational organizations, provided that these service organizations fail to control.

Here, a question may arise, whether the states should be in touch directly with global supranational organizations (Fig.b) or regional supranational ones (Fig.a) (the European Union, created parallel to common interest of national states). To decide on this issue, willingness of states to establish "regional supranational" organizations is important. The advantage of this approach in practice is that while encouraging regional-supranational cooperation of states based on their common interests, the problems of politically unstable nations, which negatively affect the world economy can be reduced by regional cooperation. By this way dispute dynamics will be transferred into agreement dynamics. However, producing such an organization in a short time is not easy because of the socio-economical differences of states. The refusal of states since they are not ready, make them diffucult to cooperate. This is why states may prefer global supranational organization cooperations (Fig.b) in medium term (20-50 year). 


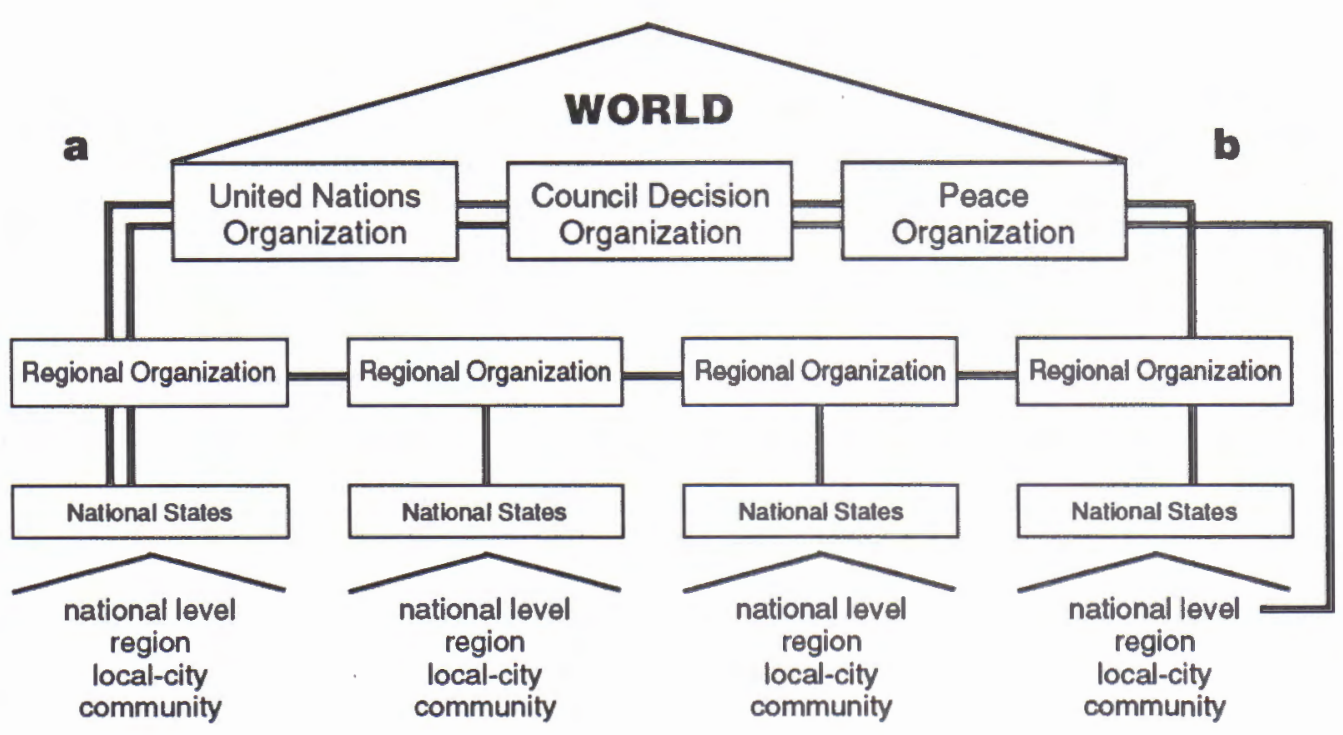

Figure. GLOBAL LEVEL (Word)

What is the relation between a regional independence of states and the supranational organizations? The reason for the existance of states is not only to provide security, but also distribution of goods and services and their control. The state and regional representatives can discuss reviewing their problems with supranational organizations beyond the national state. If the state fails to perform its commitment according to an agreement, providing international assistance to that region is not a problem. We think that in case oppressions on community and oppression on state does not intersect, and state can stay neutral on issues like environmental pollution, by the help of supranational organizations oppressions on community can be handled. In fact, the interference of supranational organizational takes place on the issues that the states involved with international agreements.

Two different approaches in integration may be obtained: "federalist" and "confederalist". In confederalist approach, the states agree to work in coordination with each other without giving up their sovereignties. Though their aim is to create a new "super power", they also aim to be in touch with the other states in the confederation while keeping their national structure. This principle actually exists within the studies of OECD and the Council of Europe. We support this approach in medium term. In fact, both in federalist or confederalist approaches, equal rights and responsibilities of member states due to having equal votes, is the foundation stone of this system. 
Above, we have answered the question, what kind of globalization and by which means as by international organizations or by international conciliatory organizations. The second issue to be discussed towards globalization is the gradation. At this point, state-local gradation should be examined in our opinion. Talking about construction of subject concerning the society, the willingness to apply a planned model should come from lower society. Otherwise, whether it is at national or at international level, the willingness coming from the top is condemned to be unsuccessiul.

In the world of nations, how can the need for supranational organization arise? In order to answer this question, analysis requires to look at the individial nations. In a social agreement, the individuals are free to make cooperation, but when the social agreement becomes an association, then a mechanism forcing to obey the rules, i.e. an external authority is necessary. However, in all circumstances, the society needs to get prepared for these rules.

This issue will be discussed below at local level.

\section{Decentralization, the First Step in Globalization}

Internationalization of relations and the creation of supranational organizations caused the administration below the central government level, to think that "they might use their own authorities on issues which were previously under the national states' monopoly".

In fact, the society has changed and it resists to "hierarchy" and "dependence". This change is trying to be explained by the principle of "subsidiarity", a term which is not definetely explained. It means to "prefer the base instead of the peak". Thus, searching for the proper grade in order to apply the authority, and selecting a higher grade only when the lower administration cannot practice their authorities is important.

The conditions for transfering the central government authorities are generally considered more serious in local government literature. The central government, which makes the position of holding the authority in its hand an issue of prestige, uses this authority as a threating factor and generally transfers very hardly. In fact, on the issue which local and joint services local government can perform, the transfer of large scale services and services which that it cannot perform to the central government seems more rational. This is closely related with the factors of democracy, openness and efficiency. Towards globalization, which is closely related with democratization, central democratization cannot be expected without a local de$m c$, ratization. The success rate of globalization will increase as much as the central government participates in democratization. 
The local independence does not create a dispute between the state and local government. The state has its own duties like providing peace, social order and security while tha local governments are responsible for services like planning, culture, housing, environment and education. In fact, the state exists to provide its citizens with secured and healthy conditions for humanly life (Stockholm, 1972). What is demanded is to produce a conciliatory cooperation for the effective distribution of goods and services. Organizations supporting cooperation in such relations have importance at local, national and international scale.

The surveillance of central government which makes it difficult to locally apply the "subsidiarity" principle is likely to be a financial problem of local government. Keeping the authorities as close as possible to citizen is also parallel to the transfer of authorities taken from the state only to governance and controlled by the elected representatives.

If there is a tendency for creating an intermediate grade in the application of the subsidiary principle, the subject of local self-government regarding this intermediate grade mostly called as "regional" will attract attention. In short, though central government have responsibility in the destroy of urban issue by megatowns and in the change of policies causing poverty, in increasing local government's capacity, giving them the chance to find effective solutions in local-urban problems, and increasing local oppurtunities are the central government's responsibilities.

Since the roots of problems and solutions pointed by the Rio Declaration, Agenda 21, generally depend on local activities, the participation and cooperation of local authorities for reaching the foreseen targets becomes a determining factor. For this reason until 1996, the local authorities in each country aim to meet the individuals, the local organizations, and the private sector in their regions to provide agreement on "Local agenda 21". It is foreseen that the United Nations and the other related organizations will start programs for increasing cooperation among local authorities, supporting them and forming capacity about the local environment governance. Therefore, especially in order for the underdeveloped countries to be able to complete their studies on this subject, the international cooperations will be strengthened.

Another point related to the increasing importance of localization in services is the activities of the volunteer organizations. The role of volunteer organizations, from which so much is expected not only at local-regional but also at international level, needs to be examined.

\section{Globalization and Volunteer Organizations}

People, with their own efforts, willingness and decisions, feel social responsibility and perform volunteer activities in order to affect the managers and even 
to guide them. The issue of environment, closely related with the issues of development, protection, etc., is an important issue on which the individuals having different culture undoubtly agree on.

Though the volunteer activities regarding the environmental protection appeared since the second half of the nineteenth century, volunteer activities today, started at the end of the 1960s. Volunteer organizations are named as "the third sector" after the public and private sectors in democratic countries.

Volunteer organizations, not only at local, but also at national and international levels contribute to globalization through their societal interest and responsibilities. Their effectiveness in democratization through education of society cannot be disregarded.

In the last ten years of the twentieth century, democracy and human rights are basic concepts that are definitely accepted by all the nations. Volunteer organizations are the necessary factors of democratic society organizations. In all the developed and developing countries the environmental volunteer organizations have significant roles. Some of the big international volunteer organizations not only apply their own projects, but also financially support other volunteer organizations in various countries.

The WWLF (World Wild Life Fund), based in Switzerland, can be shown as an example. Also, the ELCI (Environment Liason Center International), based in Nairobi having close relations with the United Nations Environmental Program-UNEP, provide aid for projects of volunteer organizations. The United Nations system gives priority to volunteer organizations. Either the United Nations Development Program (UNDP) or the United Nations Environmental Program (UNEP) declares clearly that volunteer organizations have a seperate place in their policies and practices ${ }^{12}$.

An important facility provided by the United Nations provide for environmental volunteer organizations which is the "NGOs Small Grants Program" within the GEF (Global Environmental Facility). Various projects of volunteer organizations in the countries included in this program are financed by the GEF funds.

Another organization that the volunteer organizations are interested in is the World Bank. The activities of the World Bank are closely examined in order not to give any damage to the environment. This public pressure caused the World Bank to apply environmental protection policies.

The volunteer organizations can stay out of the political pressure and can easily contact with the public. The volunteer organizations by establishing relations both 
at national and international level through lobbying, can affect the decision-makers and can include environmental protection principles in the public policies.

There are successful samples in the world regarding the cooperation of local governments and volunteer organizations. Democratization and participation, in fact, can be successful when developed from the bottom not from the top. Thus, local independence in globalization is an important issue and gets more important every day.

In short, the scenario planned in globalization period is to provide local autonomy to provide national cooperation of volunteer organizations and to represent national state in supranational organizations as an honoured and equal member. At this point, two different ways for representation can be considered. The first is the representation of slates in supranational organizations with only one vote and the second is the representation of states, which is involved in the geopraphical-regional organizations, in supranational organizations.

\section{Conclusion}

Globalism, in fact, is a "uture program" which will cover a very long time. Today this program, is considered as if realised. As a matter of fact, globalism should be considered as a "period policy". The global preparations are "the global order" policies to create this period.

The determining factors of the new world system are the liberalization and globalization. Globalization had not produced an egalitarian structure in the world. In the bipolar world, the problem of development is very important. Actually, within the framework of "the development and underdevelopment" dilemma, division of the world causes big problems. The unequal and unjust world order creates danger for the common peace, security and humanity. This period has interested everyone.

The coming century (21st) is subject to a contradiction, which on the one hand the national economies in world are going towards global integration, and on the other hand, there will be ethnic demands and nationalism. The ideological disputes seem to be replaced by ethnic nationalist trends. The sovereign nation-states seem to be in difficulty in executing two historical functions within liberal democratic systems. The nation-state is too big for local identity and too small for to fight with global economic powers. In other words, it is considered that the public life is not an arena where the big targets are expressed and the public interest does not have a common meaning any more.

The sovereignty in the twentieth century is being destroyed from the top by globalization of world economy, and from the bottom by the rise of ethnic groups with 
different languages and religions in the nation- state that are willing to determine their own destiny. Thus, the political agenda looks for the answer of two questions. What kind of a administration can be considered under the conditions where the most powertul states are even unable to determine their own destiny?. Moreover, by what kind of a local independence can the willingness of the public to determine their own destiny can be realised?

\section{Of the participation;}

" political aspect; the nation-state, when participating in a supranational cooperation should participate as a member with equal rights and responsibilities. Also, each individual must be a world union citizen having equal rights besides being a citizen of his own country. In practice, taking the freedom under guarantee is important.

* economical aspect; disorganization of the economies of member states can be possible. For the success of participation the states should be prepared for structural alterations, and the plans of adaptation should be made accordingly. Otherwise, social eruption may be obtained.

Moreover, the concept of development begins to make sense in relation with cultural life. Today, it is accepted that not only labour of people but also their cultural identities which make up their world views, should be taken into consideration. The participation of people in development projects regarding their future, is a "sine qua non" condition beyond being a wish for the possibility of applying these projects. Many of the UNESCO member states since the 1960s had involved the relation of development and culture in their projects. This evolution came to conclusion by the World Conference on Culture Policies which was held in Mexico in 1982. The strategy, offered to apply in the program of the World Cultural Development in 10 years in the Mexico Conference, is a result of these determinations ${ }^{13}$. The exchange of cultures by means of regionalism emergence of blocks will cause a synthesis including different cultures.

Cooperation for the most time is interesting, for example for the European Un. ion. Another important point is that many countries which cannot fulfill the geopraphical condition to be a European country besides the other conditions wish to be included in this system. Thus, the practice of cooperation-agreement seems possible through the support of the system, where the community/state (society) interests are protected and agreement is provided.

Capitalism which is based on creating a universal mankind, an aim in globalization program, seems to be hindering fact due to its conflicts. The solution is nei- 
ther, "nationalism", nor "hierarchic structure", nor "pressure". The solution is globalism which will remove all these mechanisms. This can be achieved by the integration of states with common interest whenever possible.

The point where the demands of integration and nationalization intersect is the solution. This is federalism at regional states level and confederalism at global level. The system where legislation, execution and jurisdiction are separated and mutually controlled may be carried to global level. However, all states in the world can not get prepared for such a system in a short term, except the European Union. Thus, in the medium term, "nation-state/global organization model" (Fig.b) is proper. For participation in the long term (after 50 years), at both regional-nation states level and at global level, "federalist" approach scenarios can be written. Today, by the Council of Europe and supranational organizations, a confederalist approach at a global level can be experienced for applying the universal ideas.

Key words; "equality", "4reedom-responsibility" and "fraternity". 